\title{
Peningkatan Branding Produk Untuk Promosi Usaha Mikro Kecil Menengah (UMKM)
}

\author{
Irwansyah', Muchamad Zainul Rohman², Wahyuni Eka Sari*3 \\ 1,2,3Program Studi Teknologi Rekayasa Komputer, Politeknik Negeri Samarinda \\ *e-mail: wahyunisari52@gmail.com³
}

\begin{abstract}
The branding of a product or service is now more creative. One of them is using video. The right video can give potential buyers a positive perspective. However, there are obstacles in making attractive branding with videos, namely the ability to package attractive videos such as editing sound and images, dubbing and adding text. Another obstacle is the distribution of the video itself. Video creation sometimes requires applications with large resources. Meanwhile, as micro, small and medium enterprises (MSMEs), it is still rare to have computers with high enough specifications. As a solution to this problem, community service activities were carried out by the Samarinda State Polytechnic team to MSME owners in the city of Samarinda using the Kinemaster. The implementation of this activity is carried out for one day to meet face to face with online mentoring for one week. The method of implementation is carried out by lectures, practices, discussions and questions and answers. This intensive service was given to 35 participants. A total of 28 participants succeeded in making business product branding videos with a duration of 1 to 2 minutes.
\end{abstract}

Keywords: branding; kinemaster; micro; samarinda; video

\begin{abstract}
Abstrak
Branding suatu produk maupun jasa kini sudah jauh lebih kreatif. Salah satunya menggunakan video. Video yang tepat dapat memberikan perspektif yang positif kepada calon pembeli. Namun terdapat kendala dalam membuat branding menarik dengan video yaitu teknik kemampuan mengemas video yang menarik seperti melakukan editing suara dan gambar, melakukan dubbing serta menambahkan teks. Kendala lain yaitu dalam hal distribusi video itu sendiri. Pembuatan video terkadang membutuhkan aplikasi dengan resource yang besar. Sedangkan sebagai pelaku usaha mikro kecil menengah (UMKM), masih jarang yang memiliki komputer dengan spesifikasi yang cukup tinggi. Sebagai solusi dari permasalahan ini, maka dilakukan kegiatan pengabdian pada masyarakat oleh tim Politeknik Negeri Samarinda kepada pemilik UMKM di kota Samarinda menggunakan aplikasi Kinemaster. Pelaksanaan kegiatan ini dilakukan selama satu hari untuk tatap muka dengan pendampingan secara online selama satu minggu. Metode pelaksanaan dilakukan dengan ceramah, praktik, diskusi dan tanya jawab. Pengabdian secara intensif ini diberikan kepada 30 peserta. Sebanyak 28 peserta berhasil membuat video branding produk usaha dengan durasi 1 sampai 2 menit
\end{abstract}

Kata kunci: branding; kinemaster; mikro; samarinda; video.

\section{PENDAHULUAN}

Branding Pemasaran produk dengan video dapat meningkatkan minat konsumen terhadap suatu layanan jasa atau barang karena konsumen dapat memahami fungsi dari produk melalui alur cerita video. Sehingga branding produk dengan video ini dapat meningkatkan minat pembeli untuk membeli produk. Branding produk menggunakan video digunakan pada berbagai bidang antara lain: promosi produk kerupuk Amplang (Watulinga et al., 2017), video pembelajaran (Fauzan \& Rahdiyanta, 2017) (Mutia et al., 2018), pelatihan instalasi listrik (Febrianto et al., 2020), promosi film (Permana et al., 2019b) dan produksi film (Permana et al., 2019a), promosi event organizer (Purwana \& Wibowo, Agus, 2014), video profil SMP IT (Ahmad Zamsuri et al., 2018), sampai dengan promosi sebuah kota yaitu kota Serang (Kausar et al., 2015).

Pembuatan video yang menarik tidak mudah. Perlunya, keahlian dalam mengemas efek, suara, dan gambar pada video sehingga menghasilkan video yang baik. Kendala lain yang dihadapi dalam pembuatan video yaitu dibutuhkan komputer multimedia dengan spesifikasi yang tinggi. 
Hanya Sebagian kalangan terbatas yang memiliki komputer yang mumpuni untuk editing video dikarenakan harga yang cukup tinggi.

Kendala ini yang dihadapi masyarakat (mitra) melalui Komunitas Tangan Diatas Samarinda (TDA). Sehingga pada kegiatan pengabdian masyarakat ini ditawarkan solusi yaitu pembuatan video menggunakan aplikasi kinemaster. Kinemaster adalah aplikasi editing video berbasis android. Peserta dapat dengan mudah mendownload aplikasi ini di playstore kemudian menginstal di smartphone. Aplikasi ini bersifat gratis untuk beberapa fitur. Aplikasi ini tidak membutuhkan alat bantu lainnya. Sehingga peserta dapat langsung mengedit video yang tersimpan di smartphone mereka.

TDA merupakan organisasi non-profit bidang enterprenuer yang tersebar di 96 kota di Indonesia dengan anggota aktif di Samarinda yaitu 200 UMKM. Komunitas ini juga tergabung dalam komunitas Relawan Teknologi dan Informasi Kalimantan Timur, yang merupakan binaan Dinas Kominfo Provinsi Kaltim. Alamat kantor organisasi ini berlokasi di Jalan Juanda, Samarinda. Pada pengabdian ini, kelompok masyarakat yang dituju adalah pemilik Usaha Mikro Kecil Menengah (UMKM). Berikut ini gambaran kemitraan Politeknik Negeri Samarinda dengan mitra pengabdian dijelaskan pada Gambar 1.

Berdasarkan Gambar 1, Politeknik Negeri Samarinda dibawah naungan Ristekbrin melakukan koordinasi dengan Diskominfo Provinsi Kaltim yang diwakili oleh Relawan TIK Kaltim dan TDA Samarinda untuk memberikan pelatihan ke masyarakat. Pada pengabdian masyarakat ini dilakukan pembuatan video yang mendeskripsikan produk layanan jasa pada salah satu UMKM yaitu Kedai Osawo di Samarinda

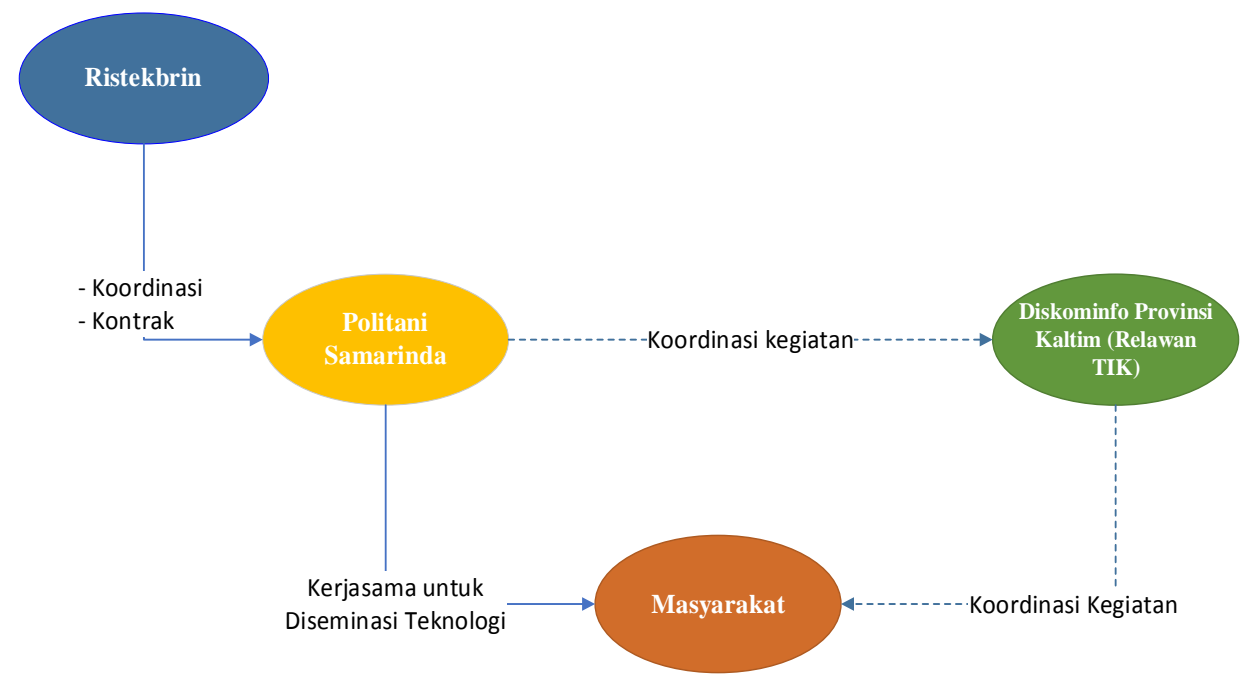

Gambar 1. Alur Kegiatan Produk Teknologi Yang Didiseminasikan Ke Masyarakat

Berdasarkan permasalahan yang dihadapi mitra, ditawarkan solusi antara lain: 1. Proses download dan install aplikasi editing video 2. Pengenalan aplikasi untuk editing video dalam bentuk presentasi 3. Pelatihan editing video menggunakan aplikasi Kinemaster 4. Evaluasi kemampuan peserta pelatihan dengan pengujian skill/kemampuan dalam editing gambar dan editing video.

\section{METODE PELAKSANAAN}

Berikut ini pada Tabel 1 uraian permasalahan mitra dan solusi yang diberikan oleh tim pengabdian Politeknik Negeri Samarinda serta metode yang digunakan. 
Tabel 1. Permasalahan Solusi dan Metode Pengabdian

\begin{tabular}{clll}
\hline No. & Permasalahan mitra & \multicolumn{1}{c}{ Solusi } & Metode \\
\hline 1 & $\begin{array}{l}\text { Mitra kesulitan mendownload dan } \\
\text { menginstal aplikasi }\end{array}$ & $\begin{array}{l}\text { Memberikan pelatihan } \\
\text { mendownload melalui } \\
\text { playstore }\end{array}$ & $\begin{array}{l}\text { Presentasi, } \\
\text { praktek, diskusi }\end{array}$ \\
2 & $\begin{array}{l}\text { Mitra belum mampu memodifikasi } \\
\text { gambar agar menarik dan mudah } \\
\text { dipahami oleh warga }\end{array}$ & $\begin{array}{l}\text { Memberikan pelatihan } \\
\text { menggambar dan editing } \\
\text { gambar serta obyek }\end{array}$ & $\begin{array}{l}\text { Presentasi, } \\
\text { praktek, diskusi }\end{array}$ \\
3 & $\begin{array}{l}\text { Menggunakan canva } \\
\text { dokumentasi hasil kegiatan untuk } \\
\text { publikasi dalam bentuk video }\end{array}$ & $\begin{array}{l}\text { Memberikan pelatihan } \\
\text { editing video hasil kegiatan } \\
\text { menggunakan aplikasi } \\
\text { kinemaster }\end{array}$ & $\begin{array}{l}\text { Presentasi, } \\
\text { praktek, diskusi }\end{array}$ \\
\hline
\end{tabular}

Kegiatan pengabdian masyarakat ini akan dilakukan dengan mengadakan Pelatihan Video Grafis untuk Smart Branding di kota Samarinda kepada masyarakat yang merupakan pelaku UMKM. Pemberian materi dilakukan dalam ruangan, yang dibagi menjadi 2 sesi. Materi pada sesi pertama untuk pengenalan aplikasi editing foto dan teknik-teknik dalam proses editing foto, materi pada sesi kedua praktek mengambil gambar untuk video, membuat alur cerita dan mengedit video. Hasil pelatihan yang diperoleh dapat meningkatkan skill dan pengetahuan Mitra tentang desain grafis dalam proses pembelajaran selanjutnya.

1. Presentasi

Langkah awal dalam membuat video yaitu, narasumber akan memperkenalkan kebutuhan aplikasi yang akan digunakan oleh peserta. Narasumber juga akan menjelaskan spesifikasi minimum perangkat keras yang dapat digunakan untuk melakukan proses editing gambar dan editing video. Setelah peserta memahami persiapan awal maka kegiatan dilanjutkan dengan presentasi materi mendownload dan menginstal aplikasi serta editing video

2. Praktik

Narasumber menggunakan teknik pengerjaan secara langsung atau praktek pembuatan video dan editing video dalam kegiatan pengabdian ini. Narasumber terlibat langsung mempraktek cara menggambar objek, mewarnai objek, memotong scene untuk video dan teknik-teknik lainnya. Setiap peserta akan didampingi oleh beberapa mahasiswa dan anggota pengusul 1 serta anggota pengusul 2.

Salah satu solusi yang dapat dilakukan adalah membekali peserta dengan pengetahuan tentang desain grafis dan editing video dalam bentuk kegiatan pelatihan bagi pelatih (Training of Trainee - TOT). Sehingga diharapkan peserta yang dilatih dapat memberikan ilmunya ke lapisan masyarakat yang lebih luas.

3. Alat dan Bahan

Kegiatan pengabdian pada masyarakat ini membutuhkan alat dan bahan antara lain: Kebutuhan perangkat keras yaitu smartphone bersistem operasi android, Media penyimpanan data sebanyak 30, Media multimedia untuk menggambar sebanyak 30. Kebutuhan perangkat lunak: Aplikasi kinemaster untuk editing video ditunjukkan pada Gambar 2 dan aplikasi Canva untuk editing gambar ditunjukkan pada Gambar 3. Pelaksaan pengabdian juga membutuhkan aplikasi zoom, microphone dan sound system. 


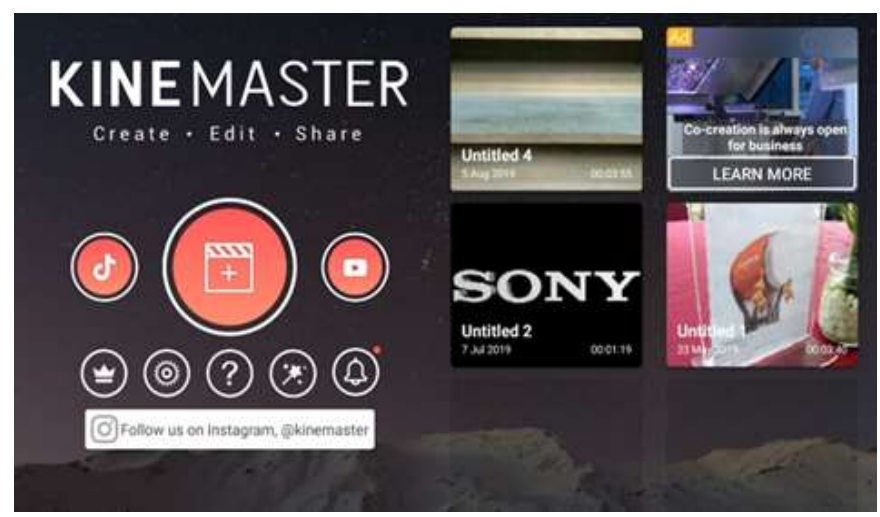

Gambar 2. Tampilan Aplikasi Adobe Premiere

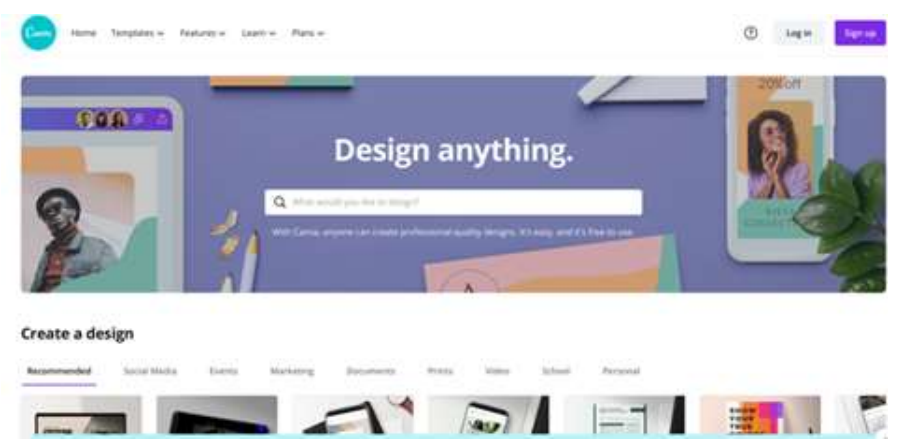

Gambar 3. Tampilan Aplikasi Adobe Photoshop

4. Waktu dan Tempat

Kegiatan pengabdian masyarakat dilaksanakan secara online melalui aplikasi Zoom Meeting. Pada hari Jumat, 04 September 2020, jam 09.00 - 16.00.

5. Peserta

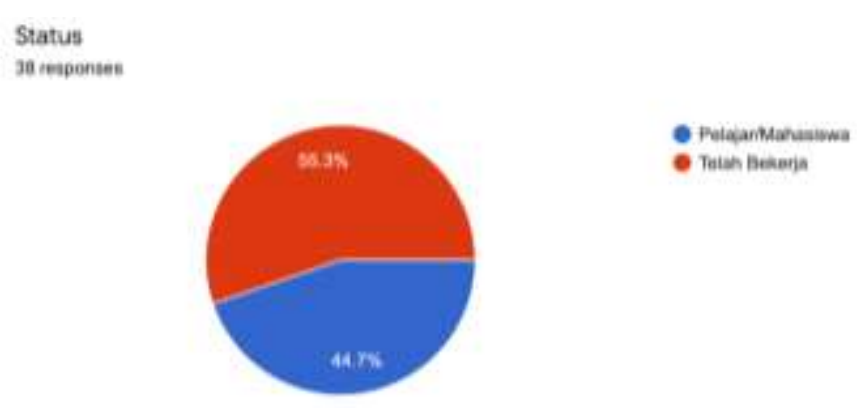

Gambar 4. Grafik Status Pekerjaan Peserta Pelatihan

Kegiatan pengabdian masyarakat ini dilakukan adalah dosen dan perwakilan mahasiswa Program Studi Teknologi Rekayasa Komputer, Politeknik Negeri Samarinda. Peserta yang hadir dari UMKM bidang jasa servis smartphone dan komputer, produk makanan dan minuman, produk tenun. Berikut ini grafik pendaftaran peserta berdasarkan status pekerjaan pada Gambar 4.

Rentang usia peserta adalah 40 tahun sampai dengan yang termuda 17 tahun. Status pekerjaan peserta antara lain: wirausaha, pustakawan, pegawai negeri sipil, pelajar. Pendaftaran dilakukan melalui Google Form (Sari, 2020) 


\section{HASIL DAN PEMBAHASAN}

Kegiatan pengabdian pada masyarakat ini merupakan program tahunan dari politani samarinda sebagai salah satu sarana agar terciptanya Tri Dharma Pendidikan Tinggi. Hasil dari kegiatan pengabdian masyarakat ini antara lain:

1. Tingkat kehadiran dan partisipasi peserta sekitar 75\%. Dari sejumlah 38 peserta yang mendaftar pada Google Form (Sari, 2020), terdapat 35 peserta yang hadir.

2. Berdasarkan wawancara kepada peserta, meningkatnya kemampuan pengambilan gambar dan video 28 peserta dari 35 peserta

3. Sebanyak 30 peserta merasakan kemampuan dalam editing gambar di aplikasi Canva meningkat.

4. Sebanyak 25 peserta merasakan kemampuan dalam editing video meningkat.

Hasil yang diperoleh berdasarkan survei ke peserta pelatihan seminggu setelah pelaksanaan. Kegiatan workshop diadakan selama satu hari. Kemudian dilakukan pendampingan selama satu minggu setelah workshop oleh pemateri. Peserta mendapatkan fasilitas berupa modul pelatihan. Peserta tergabung kedalam grup whatsapp untuk mempermudah konsultasi pelatihan. Pelatihan dibagi menjadi beberapa tahapan. Hal ini agar mempermudah peserta dalam menyerap materi pembelajaran. Berikut ini pada Tabel 2 dijelaskan alur kegiatan dengan durasi waktu.

Tabel 2. Daftar Kegiatan Pelatihan

\begin{tabular}{llc}
\hline No & \multicolumn{1}{c}{ Judul Kegiatan } & Waktu (menit) \\
\hline 1 & Pentingnya video branding & 15 \\
2 & Instalasi aplikasi untuk editing video & 30 \\
3 & Mengambil video dan gambar & 30 \\
4 & Membuat alur cerita video & 20 \\
5 & Memasukkan video dan gambar ke jendela editor & 10 \\
6 & Memisahkan video dengan suara & 30 \\
7 & Memotong klik video & 60 \\
8 & Memasukkan backsound yang ke dalam video & 30 \\
9 & Menambahkan gambar dan tulisan ke dalam video & 20 \\
10 & Mengekspor video ke dalam format mp4 & 30 \\
& Total waktu & 275 menit \\
\hline
\end{tabular}

Berdasarkan Tabel 2, total waktu yang dibutuhkan selama workshop adalah 275 menit atau sekitar 4.58 jam dan untuk pendampingan secara online selama satu minggu dibutuhkan waktu rata-rata 4 jam perhari. Berikut ini pada Gambar 5 cuplikan proses editing video.

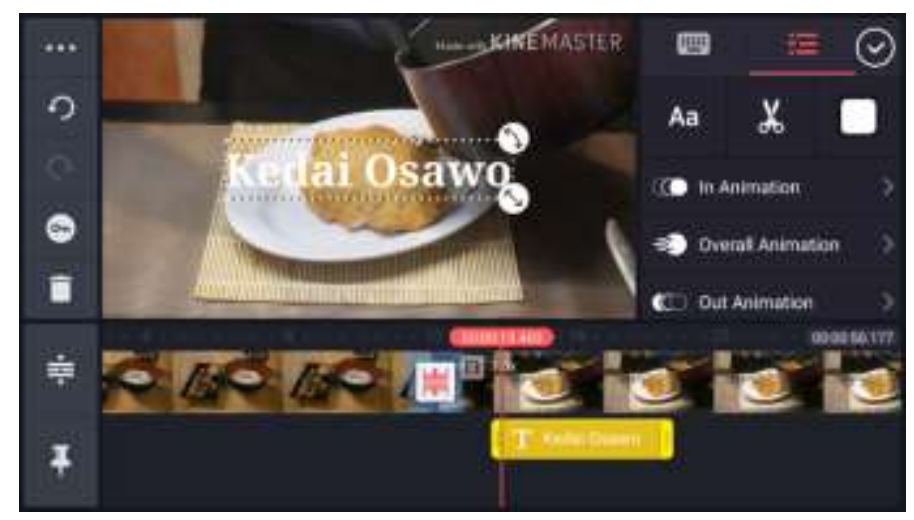

Gambar 5. Proses Editing Video 
Pada Gambar 5 proses editing yang dilakukan adalah menambahkan tulisan ke timeline video. Pada gambar tanda merah adalah text yang sudah kita masukkan ke dalam jendela timeline. Selanjutnya, peserta memasukkan gambar ke dalam timeline agar dalam video nanti bisa digunakan sebagai gambar intro, watermark dan lain lain. Caranya sama seperti ketika ingin mengedit video, yaitu masukkan gambar ke dalam jendela source, setelah dari jendela source peserta dapat melakukan drag and drop ke jendela timeline.

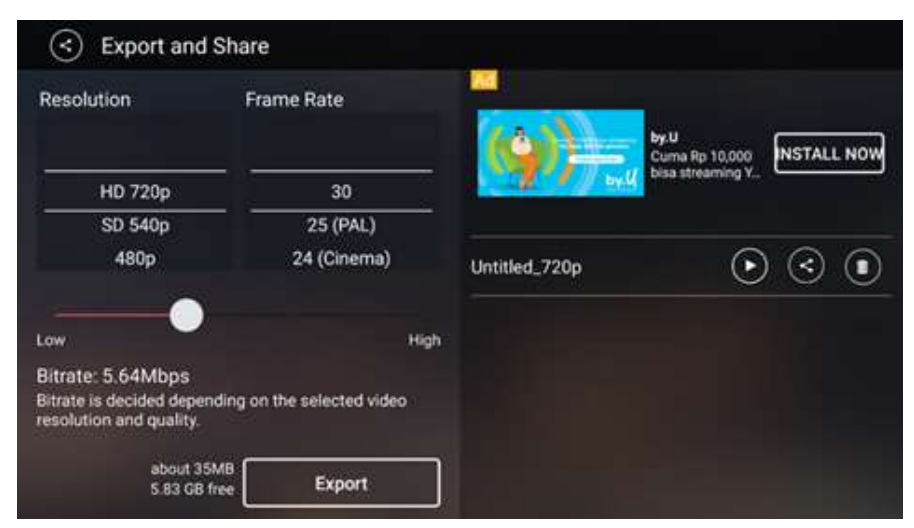

Gambar 6. Hasil Akhir Video

Berdasarkan Gambar 6, video yang dihasilkan adalah video promosi usaha produk makanan dengan durasi 1 menit 59 detik. Hasil akhir dari video UMKM siap diposting melalui akun Instagram milik Kedai Osawo. Selanjutnya pada Gambar 7 adalah foto hasil kegiatan pengabdian.

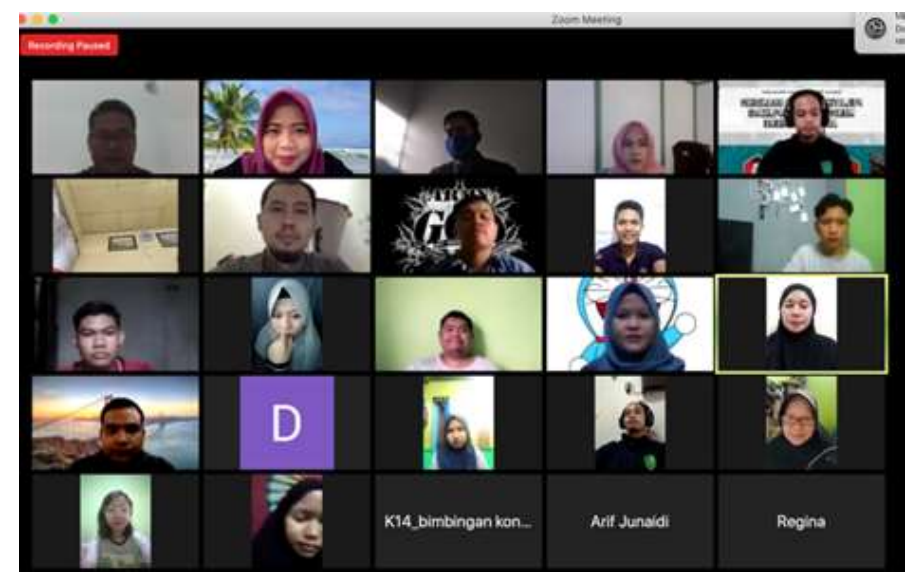

Gambar 7. Pelaksanaan Kegiatan Pengabdian

Hasil kegiatan juga dimuat pada media cetak dan online Samarinda Pos (Pos, 2020). Pelaksanaan pengabdian kepada masyarakat ini terdapat beberapa kendala, antara lain: kendala jaringan internet beberapa peserta ketika pelaksanaan pelatihan menggunakan aplikasi zoom. Panitia menfasilitasi dengan memberikan rekaman selama pelatihan agar peserta dapat mengulangi secara mandiri. Aplikasi kinemaster versi tidak berbayar masih memiliki keterbatasan sehingga kedepannya agar proses editing menghasilkan video yang lebih baik, dapat menggunakan aplikasi versi berbayar.

\section{KESIMPULAN}

Kegiatan Peningkatan Branding Produk Untuk Promosi Usaha Mikro Kecil Menengah (UMKM) Di Kota Samarinda mendapat respon positif dari semua pihak sehingga dalam 
kegiatannya dapat dilaksanakan sesuai jadwal yang sudah disepakati. Pengabdian pada masyarakat ini cukup berhasil dilakukan dengan kehadiran mencapai $75 \%$ dan $71 \%$ peserta merasakan kemampuan editing video meningkat. Produk yang dihasilkan dari pengabdian ini dapat langsung disebarluaskan melalui media sosial seperti Instagram atau facebook. Adapun saran bagi berlangsungnya kegiatan ini adalah meningkatkan skill teknik pengambilan video dengan melakukan pengambilan video secara berulang dan mengeksplor kemampuan editing video dengan aplikasi lain sehingga terbiasa melakukan editing video pada berbagai tampilan aplikasi editing video.

\section{UCAPAN TERIMA KASIH}

Ucapan terima kasih kepada Program Pengabdian Masyarakat Kemitraan Mandiri 2020 dari Politeknik Negeri Samarinda.

\section{DAFTAR PUSTAKA}

Ahmad Zamsuri, Wenni Syafitri, \& Febrizal As-Syam. (2018). Pelatihan Video Editing Di Smp It Madani. Dinamisia: Jurnal Pengabdian Kepada Masyarakat, 2(2), 310-314. https://doi.org/10.31849/dinamisia.v2i2.2984

Fauzan, M. A., \& Rahdiyanta, D. (2017). Pengembangan Media Pembelajaran Berbasis Video pada Teori Pemesinan Frais. Jurnal Dinamika Vokasional Teknik Mesin, 2(2), 82. https://doi.org/10.21831/dinamika.v2i2.15994

Febrianto, G., Sulton, S., \& Praherdiono, H. (2020). Pengembangan Media Video Pembelajaran untuk Pelatihan Instalasi Tenaga Listrik. JKTP: Jurnal Kajian Teknologi Pendidikan, 3(2), 149157. https://doi.org/10.17977/um038v3i22020p149

Kausar, A., Sutiawan, Y. F., \& Rosalina, V. (2015). Perancangan Video Company Profile Kota Serang Dengan Teknik Editing Menggunakan Adobe Premier Pro Cs 5. Jurnal PROSISKO, 2(1).

Mutia, R., Adlim, A., \& Halim, A. (2018). Pengembangan Video Pembelajaran IPA Pada Materi Pencemaran dan Kerusakan Lingkungan. Jurnal Pendidikan Sains Indonesia, 5(2), 110-116. https://doi.org/10.24815/jpsi.v5i2.9825

Permana, R. S. M., Puspitasari, L., \& Indriani, S. S. (2019a). Pelatihan Post-Produksi (Audio-Visual Editing) Film Indie di Armidale English College Soreang, Bandung. Jurnal Pengabdian Pada Masyarakat, 4(1), 19-28. https://doi.org/10.30653/002.201941.88

Permana, R. S. M., Puspitasari, L., \& Indriani, S. S. (2019b). Strategi Promosi Pada Tahapan PraProduksi Film 'Haji Asrama' (HAS). ProTVF, 2(2), 145. https://doi.org/10.24198/ptvf.v2i2.20818

Pos, S. (2020, September 4). Dosen TI Polnes Berikan Pelatihan Video Grafis. https://sapos.co.id/2020/09/06/dosen-ti-polnes-berikan-pelatihan-video-grafis/

Purwana, D., \& Wibowo, Agus, S. (2014). Pelatihan Berwirausaha Edit Video Shooting Dan Event Organizer Bagi Tenaga Kerja Indonesia (TKI) Purna Di Sukabumi Jawa Barat. Jurnal Sarwahita, 13(1), 49-56.

Sari, W. E. (2020). Formulir Pendaftaran Pelatihan Video Grafis 2020. https://forms.gle/ps4bhJXs5zF5t9wZA

Watulinga, A. O., Ugiarto, M., \& Cahyono, B. (2017). Pembuatan Media Video Profil pada Perusahaan Amplang sebagai Media Pengenalan Produk. In Jurti (Vol. 1, Issue 1, pp. 48-52). 